\title{
Effect of Comfort Care Integrated with the Holy Qur'an Recitation on Comfort of Muslim Patients under Mechanical Ventilation: A Pilot Study
}

\author{
J unaidy Suparman Rustam¹, Waraporn Kongsuwan'2, Luppana Kitrungrote ${ }^{3}$ \\ 1. Master Student of Nursing Science (International Program), Faculty of Nursing, Prince of Songkla University, Hatyai, Thailand. \\ 2. Associate Professor, Faculty of Nursing, Prince of Songkla University, Hatyai, Thailand \\ 3.Assistant Professor, Faculty of Nursing, Prince of Songkla University, Hatyai, Thailand
}

*Correspondence: J unaidy Suparman Rustam, Faculty of Nursing, Prince of Songkla University, Hatyai, Thailand. Email: adhiejunaidy@gmail.com

\section{A R T I C L E I N F O ABSTRACT}

Article history:

Received: 20 July 2017

Revised: 02 January 2018

Accepted: 14 January 2018

Key words:

Artificial

Islam

Patient comfort

Respiration
Background: Most patients experience decreased physical, psychosocial, and spiritual comfort while receiving mechanical ventilation. Regarding the Muslim patients, diminished comfort might be associated with alterations in performing daily rituals, such as saying prayers (salat) and reciting the Holy Qur'an. This pilot study aimed to determine the effects of comfort care integrated with the Holy Qur'an recitation on comfort in Muslim patients being mechanically ventilated.

Methods: This quasi-experimental study was performed on a group of participants using pretest-posttest design. The samples consisted of ten Muslim patients under mechanical ventilation who met the inclusion criteria. Each participant was provided with the comfort care integrated with the Holy Qur'an recitation for three days. A modified version of Shortened General Comfort Questionnaire was utilized to evaluate comfort of the participants. The data were analyzed by SPSS using paired t-test.

Results: Mean score of total comfort increased significantly after receiving the comfort care integrated with recitation of the Holy Qur'an ( $t=11.42, p=0)$. In addition, mean score of each context of comfort (i.e. physical, psychospiritual, environmental, and sociocultural comforts) also augmented significantly post-intervention.

Conclusion: This pilot study showed that the comfort care integrated with the Holy Qur'an recitation can be an effective way of enhancing comfort of Muslim patients under mechanical ventilation.

\section{Introduction}

Mechanical ventilator is a lifesaving machine frequently used as a treatment modality for patients with respiratory failure. ${ }^{1}$ On the other hand, $96 \%$ of the patients under mechanical ventilation reported decreased comfort during treatment in the previous study. ${ }^{2}$ The discomfort might result from various causes, such as pain, dyspnea, anxiety, feeling lonely, and sleep disturbance due to sensory overload as well as deprivation. ${ }^{3,4}$ If nurses do not manage this condition effectively, it can lead to feelings of panic, depression, agitation, delirium, ${ }^{5}$ and unplanned extubation. ${ }^{6}$

Meeting the comfort needs by appropriate nursing care would enhance the patients' comfort. ${ }^{7}$ Katherine Kolcaba $^{8}$ describes in the Theory of Comfort that the comfort needs of patients can be categorized in four contexts according to the patients experience with comfort. These categories include physical, psychospiritual, environmental, and sociocultural. Therefore, in order to improve patients comfort, nursing comfort care is applied to target various comfort needs at once. ${ }^{9}$

A review study by Ponte et al. reported that numerous studies have applied Kolcaba's comfort care as the guiding framework. These studies have investigated the impact of this theory on enhancing comfort aspects including physical, psychospiritual, environmental, and sociocultural comforts in various settings. ${ }^{10}$ Nevertheless, the literature encompasses a limited number of studies about comfort in mechanically ventilated patients.

A study by Coyer et al. ${ }^{11}$ has listed several basic interventions that are commonly executed to promote comfort in patients under mechanical ventilation, namely positioning, suctioning, and oral care. Furthermore, management of stressors including ineffective communication, sleep disturbance, and isolation is mentioned. ${ }^{11}$ 
Another study conducted by Han et al. ${ }^{12}$ examined the effect of music on the physiological response to stress and anxiety level among the patients under mechanical ventilation. They found significant differences between the studied groups in terms of vital signs and anxiety level. ${ }^{12}$ However, the role of these interventions is not prominent and may not be appropriate for all patients with different spiritual and cultural backgrounds, particularly in Muslim population.

Muslims believe that following the principles of religion is associated with comfort, pleasure, and confidence for them, especially when they are sick. ${ }^{12}$, ${ }_{13}$ This is emphasized in the verses from the Holy Qur'an, such as "Remembrance of Allah certainly brings comfort to all hearts" (Surah Ar-Ra'd, verse 28) and "And seek help (in your affairs) through patience and prayer" (Surah Al-Baqarah, verse 45).

Furthermore, Muslims believe that the sound of the Holy Qur'an recitation is beneficial in recovery from sickness, promotes good health, and has relaxing effects; even though they do not understand the meaning of the verse that is being read or recited. ${ }^{14,15}$ When the Holy Qur'an is recited aloud by a reader with a beautiful voice, stress may abate, comfort is increased, and an overall relaxation is induced. ${ }^{16}$ In addition, it may also synchronize the body rhythms including breathing and heart rate, as well as positively affecting the emotions of listener. ${ }^{17}$, 18

For Muslim patients under mechanical ventilation, the reduced comfort can be attributed to higher spiritual needs due to the difficulty of performing their daily ritual, such as saying prayers (salat) and reciting the Holy Qur'an. ${ }^{19}$ Therefore, it is important to consider the basic principles of Islam, in taking care of the Muslim patients being mechanically ventilated. It should be mentioned that several studies reported that the Holy Qur'an recitation has positive influences on Muslim patients under mechanical ventilation. ${ }^{17,18}$

Awa evaluated the effects of listening to the Holy Qur'an recitation on physiological stress response among Muslim patients in intensive care unit. The results demonstrated that there were significant differences regarding the patients' heart rate after listening to the Holy Qur'an recitation. ${ }^{18}$ The change in heart rate could be associated with the relaxation response. ${ }^{20}$ Therefore, the Holy Qur'an recitation is considered as a comforting intervention. It could be integrated into the nursing comfort care in order to enhance the overall comfort in Muslim patients under mechanical ventilation.

This pilot study aimed to examine the effect of comfort care integrated with the Holy Qur'an recitation as a brief test that focuses on the four contexts of comfort, namely physical, psychospiritual, environmental, and sociocultural comforts. The participants included the Muslim patients under mechanical ventilation. This intervention can be useful to guide nurses for promoting holistic comfort in clinical practice in mechanically ventilated patients, especially for Muslims.

\section{Methods}

\subsection{Design}

This quasi-experimental study with one-group pretest-posttest design was used to determine the effect of comfort care integrated with the holy Qur'an recitation on patients' comfort. The comfort was assessed regarding four contexts, including physical, psychospiritual, environmental, and sociocultural aspects. The participants received comfort care integrated with recitation of the Holy Qur'an for three days.

\subsection{Participants and settings}

This pilot study was conducted at two intensive care units of two public hospitals in West Sumatra, Indonesia from December 2016 to February 2017. Purposive sampling procedure was used to recruit eligible participants.

The inclusion criteria entailed: 1) Muslim patients being under mechanical ventilation, 2) age of older than 18 years, 3) being fully conscious according to Glasgow Coma Scale, 4) being hemodynamically stable, 5) not having hearing or cognitive impairments, 6) being able to write and read in the Indonesian language, and 7) absence of mental disorders. The exclusion criteria included receiving continuous sedative agents and/or continuous intravenous analgesics, in addition to extubation during the study.

The individuals who met the inclusion criteria were found in the ICUs of these two hospitals. Then, the nurses of these two selected ICUs asked the eligible patients if they were interested in this study. Afterwards, the first researcher gave an explanation to the participants regarding the purpose of the study, procedure, risks, benefits, and confidentiality. Finally, informed consents were taken from the individuals who accepted to collaborate in the study.

The sample size for this pilot study was obtained following Nieswiadomy ${ }^{21}$ who estimated that approximately ten participants should be used. Thirteen patients enrolled in this pilot study, ten of whom completed the intervention. The reason for dropout of the three patients was that they were extubated on the second day of the intervention. 


\subsection{Instruments}

Shortened General Comfort Questionnaire (SGCQ) of Kolcaba ${ }^{8}$ was modified by the researchers in order to measure comfort in this study. This tool consists of six positive and ten negative statements scaled in six responses (one to six) ranging from strongly disagree to strongly agree. The 16 items of SGCQ cover all contexts of comfort. The questionnaire comprises of four, five, three, and four items related to physical, psychospiritual, environmental, and sociocultural comfort aspects. Finally, the sum of scores was determined, so that the minimum score was 16 and the maximum score was 96 . The higher score indicates a higher level of comfort.

Content validity of the modified instrument and intervention was evaluated by a panel of four experts. They included three experts in critical care nursing, adult nursing, quantitative study design, and one expert in the Holy Qur'an recitation. The first three experts validated the modified SGCQ as well as the intervention. The fourth expert validated the content of the Holy Qur'an recitation including tajwid, pronunciations, Surah of the Holy Qur'an, and the reciter (Qari) of the Holy Qur'an. The scale of content validity index (S-CVI) was 0.92 and 1 for the SGCQ and intervention, respectively.

Afterwards, the modified SGCQ was translated into Indonesian language by back translation technique. ${ }^{22}$ Next, the researchers tested the reliability of the modified SGCQ, which showed that the Cronbach's alpha coefficient was 0.81 .

\subsection{Data Collection}

On the first day of the study one of the researchers collected the demographic and clinical characteristics of the participants primarily from the medical records. The data entailed age, gender, marital status, current medical diagnosis, ventilator mode, and the duration of using mechanical ventilation. The research assistant collected the pretest data (day one) and the post-test data (day three) by the modified SGCQ. The post-test data were taken one hour after performing the intervention.

The intervention in this study was developed based on Kolcaba's Comfort Theory and consisted several parts. Stability of the patients' hemodynamics was monitored by vital signs, including heart rate (HR), blood pressure (BP), respiratory rate (RR), and body temperature (BT). Physical functions of the patients were maintained by nursing interventions including positioning, suction, mouth care, as well as administration of analgesic and sedative medications as prescribed by the physicians. The routes of conveying patients' comfort needs, such as pen and paper or communication board were explained to the patients and their family members. The participants and their families were assured that the researcher would consider any verbal or nonverbal responses of the patients during the intervention period. The family members were involved to help the participants for ablution (wudhu) before prayers (salat). The participants' prayers (salat) performance was tried to be facilated. The patients were provided with a session of Holy Qur'an recitation (Surah AlFatihah and Surah Yasin) using headphones and MP3 player for 15 minutes.

Surah Al-Fatihah was used in this study due to the fact that it is a matchless Surah revealed in the Holy Qur'an. Muslims believe that recitation of Surah Al-Fatihah can be the best treatment for many diseases. Moreover, Surah Yasin is the 36th surah of the Qur'an and is known as the heart of the Qur'an in many narratives. ${ }^{15}$

The three-day intervention was completed by the first author for the participants. The duration of each session ranged from $45-60$ minutes as shown in Diagram 1. 


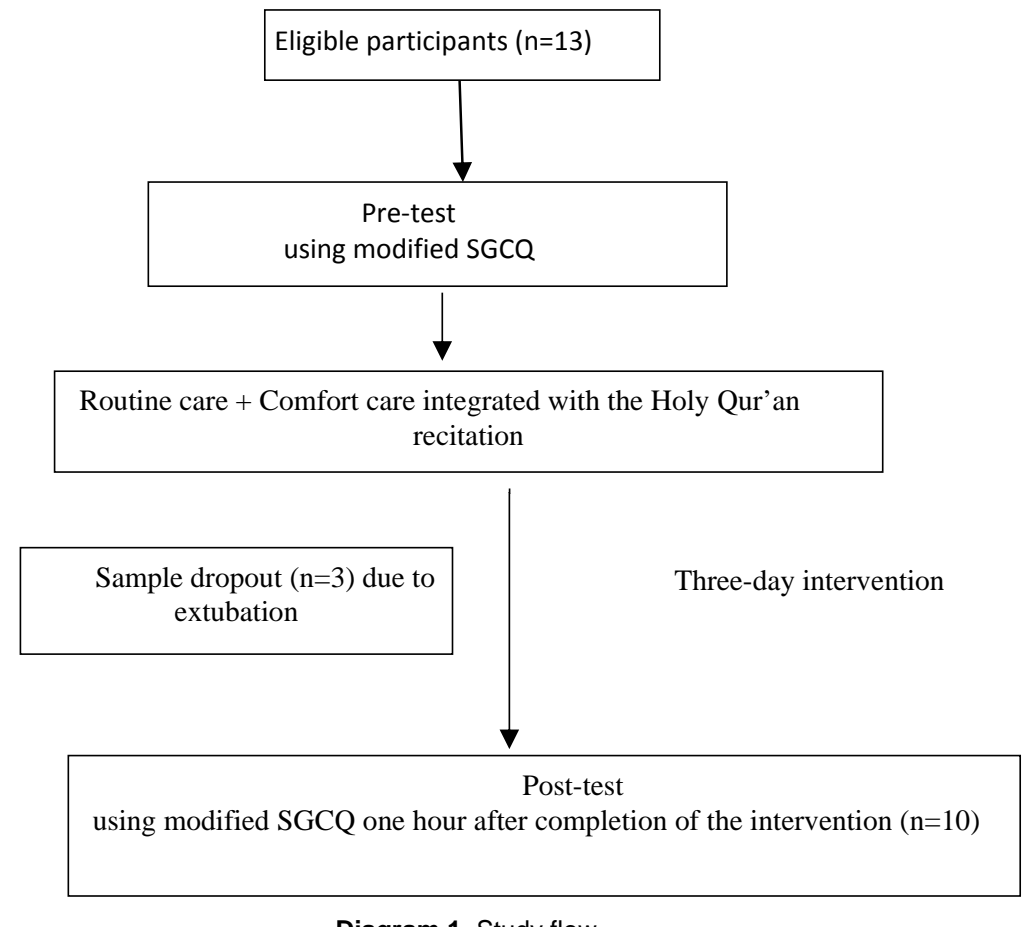

Diagram 1. Study flow

\subsection{Ethical considerations}

The present study was approved by the Ethics and Research Committee of the Faculty of Nursing, Prince of Songkla University, Thailand, and also the Faculty of Medicine, Andalas University, Indonesia. All the information, namely the procedures, risks, and benefits of the study were explained to the participants. In order to prevent the potential risks in this study, the first researcher assessed condition of the participants prior to the test and the first researcher also constantly observed the participants during the intervention.

\subsection{Statistical analysis}

The collected data were entered into the SPSS version 17.0 for Windows. Descriptive statistics were used to analyze the demographic and clinical characteristics of the participants regarding age, gender, marital status, current medical diagnosis, ventilator mode, and duration of using mechanical ventilation. The frequencies, percentages, means, standard deviations, medians, and quartiles were obtained.

The paired t-test was performed to detect any within-groups effect between the pre- and post- intervention times. P-value $<0.05$ was considered as statistically significant. The normality for paired ttest was checked by skewness and kurtosis values showing that the data sets were normally distributed.

\section{Results}

The mean age of the individuals was $58.1 \pm 12.03$ years with a range of $36-77$ years. All the ten participants were Muslims and most of them were males (70\%). According to the results, $40 \%$ of the participants had university education, and $40 \%$ were retired or housewives. Most of the patients $(60 \%)$ were in post-surgery condition and had been ventilated for one to twelve days $(\mathrm{Med}=1)$. The most common $(50 \%)$ used ventilator mode was biphasic positive airway pressure (BiPAP) as presented in Table 1.

Table 2 displays the results of comparison made between the pre- and post-intervention comfort scores among the ten participants who completed the intervention. The mean score of total comfort and each context of comfort (i.e. physical, psychospiritual, environmental, and sociocultural comforts) augmented significantly after test. 
Rustam JS et al.

Table 1. Demographic and clinical characteristics of the participants $(n=10)$

\begin{tabular}{|c|c|c|c|}
\hline Characteristics & & $\mathbf{N}$ & $\%$ \\
\hline Age & $($ Min-Max=36-77) & $\mathrm{M}=58.10$ & $\mathrm{SD}=12.032$ \\
\hline \multirow[t]{2}{*}{ Gender } & Male & 7 & 70 \\
\hline & Female & 3 & 30 \\
\hline \multirow[t]{4}{*}{ Marital status } & Married & 8 & 80 \\
\hline & Widow & 2 & 20 \\
\hline & Elementary school & 2 & 20 \\
\hline & Junior school & 1 & 10 \\
\hline \multirow[t]{4}{*}{ Educational level } & Senior high school & 3 & 30 \\
\hline & University & 4 & 40 \\
\hline & Pulmonary diseases & 1 & 10 \\
\hline & Cardiac diseases & 1 & 10 \\
\hline \multirow{4}{*}{$\begin{array}{l}\text { Current medical } \\
\text { diagnosis }\end{array}$} & Metabolic diseases & 1 & 10 \\
\hline & Post-surgery & 6 & 60 \\
\hline & Chest trauma & 1 & 10 \\
\hline & BiPAP & 5 & 50 \\
\hline \multirow[t]{2}{*}{ Ventilator mode } & CPAP & 4 & 40 \\
\hline & SIMV & 1 & 10 \\
\hline $\begin{array}{l}\text { Duration of using } \\
\text { ventilator }\end{array}$ & (1-12 days) & Med=1 & IQR=3 \\
\hline
\end{tabular}

Note: M: Mean, SD: Standard Deviation, Med: Median,

IQR: Interquartile, BiPAP: Bilevel positive airway pressure,

CPAP: Continuous positive airway pressure,

SIMV: Synchronized Intermittent-Mandatory Ventilation

Table 2. Comparison between the mean comfort scores pre- and post-intervention

\begin{tabular}{|c|c|c|c|c|}
\hline \multirow[b]{2}{*}{ Variables } & Pre-test & Post-test & \multirow[b]{2}{*}{$\mathbf{T}$} & \multirow[b]{2}{*}{$\mathbf{p}$} \\
\hline & Mean $\pm S D$ & Mean $\pm S D$ & & \\
\hline Total comfort & $51.00 \pm 5.90$ & $69.43 \pm 7.54$ & 11.42 & $0^{*}$ \\
\hline Physical comfort & $12.20 \pm 1.62$ & $16.20 \pm 1.87$ & 7.74 & $0^{*}$ \\
\hline Psychospiritual comfort & $15.80 \pm 3.23$ & $22.50 \pm 3.14$ & 8.07 & $0^{*}$ \\
\hline Environmental comfort & $9.90 \pm 2.89$ & $11.80 \pm 2.25$ & 2.89 & $0.02^{*}$ \\
\hline Sociocultural comfort & $13.10 \pm 3.35$ & $19.30 \pm 1.83$ & 6.08 & $0^{*}$ \\
\hline
\end{tabular}

P-value $<0.05$

\section{Discussion}

Findings of the current study indicated that comfort levels of Muslim patients under mechanical ventilation increased significantly after receiving the comfort care integrated with the Holy Qur'an recitation for three days. Improved comfort of the participants encompassed all contexts of comfort that can be associated with the design of the intervention in this study, which was based on
Kolcaba's comfort care. ${ }^{8}$ In her theory, Kolcaba stated that the comfort care is a holistic concept that can promote all contexts of comfort, including physical, psychospiritual, environmental, and sociocultural comfort altogether. According to the findings of the present study, this concept can be proved.

Previous studies by Ciftci et al. ${ }^{23}$ and Besel ${ }^{24}$ used Kolcaba's Theory of Comfort as the conceptual framework and utilized music as the comforting 
intervention to enhance patients' comfort while receiving mechanical ventilation. In addition, they used an instrument adopted from Kolcaba's Comfort Theory to measure comfort in their studies.

Ciftci et al. ${ }^{23}$ found that music had a positive effect on comfort score of mechanically ventilated patients. However, the comfort level of each context of comfort was not presented separately in this study. On the other hand, Besel ${ }^{24}$ investigated five mechanically ventilated patients and found no statistically significant relationship between the intervention and the changes in comfort score preand post-test. The latter result might be due to the small number of participants.

The findings of the current study demonstrated that the mean scores of psychospiritual and sociocultural comforts were significantly higher than those of physical and environmental comforts. The mentioned result among the participants might be related to integration of the spiritual and cultural aspects in the comfort care provided for the patients. Helping the individuals for saying prayers (salat) is regarded as a source of psychological support for Muslim patients. $^{25}$ Moreover, providing the opportunity for listenning to recitation of the Holy Qur'an may lead in deep spiritual influence on them. ${ }^{26}$ Furthermore, involvement of the patients' family members in our study, might have also resulted in a social interaction between the patients with their loved ones. ${ }^{4}$

In critical care setting, the Holy Qur'an recitation can be performed to acknowledge the high priority of holistic nursing and supporttive interventions in taking care of Muslim patients. ${ }^{27}$ A study by Awa ${ }^{18}$ reported that Holy Qur'an recitation did not significantly affect the physiological stress response (e.g., blood pressure, mean arterial pressure, and tidal volume), except for heart rate. However, this study recommended recitation of Holy Qur'an as a complementary practice for Muslim patients being ventilated. The author believes that it enhances comfort of the patients during treatment as it reduces patients' heart rate. ${ }^{18}$

In another study by Ariff et al. ${ }^{17}$ impact of the Holy Qur'an on hemodynamic parameters of Muslim patients under mechanical ventilation was assessed. Effects of a session of listenning to the Holy Qur'an recitation at nonspecific time during the mechanical ventilation was studied. Results of the mentioned study showed that there was no statistical difference between the mean of all four parameters (i.e., blood pressure, heart rate, oxygen saturation, and electrocardiographic changes) before and during the Holy Qur'an recitation. ${ }^{17}$

Listening to recitation of the Holy Qur'an for 15 minutes during three days was demonstrated to increase total comfort of the participants in this study. This influence was particularly observed on psychospiritual and sociocultural comfort of the individuals who were Muslims. A study performed by Alhouseini et al. showed that the alpha brain wave sinificantly augmented after listening to the Holy Qur'an recitation that results in feeling more relaxed and calm. ${ }^{28}$

Similarly, Zulkarnain et al. ${ }^{20}$ investigated and compared the influence of listening to recitation of the Holy Qur'an and classical music on human brain wave using electroencephalography. These authors indicated that the percentage of alpha brain wave raised significantly when listening to the Holy Qur'an recitation compared to the classical music [20]. It could be concluded from ther results that the Holy Quran recitation induced a significant relaxation. This impact may be due to the special effect of the Holy Quran on Muslims' heart that can lead to some hormonal and chemical alterations responsible for relaxation. ${ }^{29}$

There were several limitations in this study. For instance, according to the hospital guidelines, most of the patients received deep sedation on the first to second days of mechanical ventilation. As a resul the patients were not alert enough to answer questions and participate in this study. Therefore, the researchers had to wait until the patient received only light sedation and was alert enough to cooperate in the study. Moreover, many patients were ventilated for a short time (1-2 days), not allowing enough time for the researchers to collect data and leading to limited chance for recruiting more subjects. Additionally, the intervention could not be executed at a specific time because some of the patients needed to rest. Furthermore, some patients received the intervention from the nurses or physicians at the rest time.

\section{Conclusion}

Results of the present study revealed a significant difference between the pre- and postintervention comfort scores regarding all contexts of comfort needs. Integrating comfort care with recitation of the Holy Qur'an has a positive effect on comfort in Muslim patients under mechanical ventilation. Consequently, addressing the comfort intervention used in this study in nursing practice could be beneficial for improving the holistic comfort of Muslim patients while receiving mechanical ventilation. However, this study is a preliminary study with a small sample size. Therefore, further studies using larger sample sizes are strongly recommended in order to generalize these findings. 


\section{Conflicts of interest}

The authors declare no conflicts of interest.

\section{Authors' contributions}

Junaidy Suparman Rustam: Study design, Waraporn Kongsuwan: Data collection and analysis, Luppana Kitrungrote: Manuscript.

\section{Acknowledgments}

\section{References}

1. Pan C, Qiu H. Improve survival from prolonged mechanical ventilation: beginning with first step. Journal of Thoracic Disease 2015; 7(1): 1076-1079.

2. Ma P, Liu J, Xi X, Duc B, Yuan X, Lin H, et al. Practice of sedation and the perception of discomfort during mechanical ventilation in Chinese intensive care unit. Journal of Critical Care. 2010; 25: 451-7.

3. Wang Y, Li H, Zou H, Li Y. Analysis of complaints from patients during mechanical ventilation after cardiac surgery: a retrospective study. Journal of Cardiothoracic and Vascular Anesthesia 2015; 29: 990-4.

4. Lombardo V, Vinatier I, Baillot ML, Franja V, Ghittori IB, Dray $\mathrm{S}$, et al. How caregiver view patients comfort and what they do to improve it: a french survey. Annals of Intensive Care 2013; 3(1): 1-8.

5. Grap MJ, Blecha T, Munro C. A description of patients report of endotracheal tube discomfort. Intensive and Critical Care Nursing 2002; 2: 244-9.

6. Grap MJ, Munro CL, Wetzel PA, Best AM, Ketchum JM, Hamilton A, et al. Sedation in adults receiving mechanical ventilation: physiological and comfort outcomes. American Journal of Critical Care 2012; 21(3): 23-64.

7. Masters K. Nursing theories: A framework for professional practice United States of America: Jones \& Bartlett Learning; 2015.

8. Kolcaba K. Comfort Theory \& Practice: A Vision For Holistic Health Care and Research New York: Springer Publishing Company, Inc.; 2003.

9. Wilson L, Kolcaba K. Practical application of comfort theory in the perianesthesia setting. Journal of Perianesthesia Nursing 2004; 25(2): 164-73.

10. Ponte KM, Silvia LF. Comfort as a result of nursing care: an integrative review. Journal of Research Fundamental Care Online 2015; 7(1): 2603-14.

11. Coyer f, Wheeler MK, Wetzig SM, Couchman BA. Nursing care of the mechanically ventilated patients: what does the evidence say? part two. Intensive and Critical Care Nursing 2007; 23(2): 71-80.

12. Al-Galal SA, Alshaikli IF, Rahman AW, Dzulkifli MA. EEGbased emotional recognition while listening to Quran recitation comapred with relaxing music using valence-arousal model 4th International Conference on Advanced Computer Science Applications and Technologies 2015: 245-50.

13. Yousefi H, Abedi HA, Yarmohammadian MH, Elliot D. Comfort as a basic need in hospitalized patients in Iran: a hermeneutic phenomenology study. Journal of Advance Nursing 2009; 65(1): 1891-8.

14. Babaii A, Abbasinnia M, Hejazi SF, Tabei SR, Deghani F. The effect of listening to the voice of Quran on anxiety before cardiac catheterization: a randomized controlled trial. Health, Spirituality and Medical Ethics 2015; 2(2): 8-14
We would like to extend our special gratitude to Thailand's Education Hub for Southern Region of ASEAN Countries (TEH-AC) and the Graduate School, Prince of Songkla University, Thailand that supported this project financially. We would also like to acknowledge the nurses and medical staff of the Achmad Mochtar Hospital and YARSI Islamic Hospital in West Sumatra, Indonesia, in addition to the patients and their families for participating in this study.

15. Babamohamadi H, Sotodeshal N, Koenig Hg, Jahani C, Ghorbani R. The effect of holy Qur'an recitation on anxiety in hemodialysis patients: a randomized clinical trial. Journal of Religion and Health 2015; 54(1): 921-1930.

16. Hermatti S, Ghahfarokhi MB, Fard RK, Bertiani ZM. Spiritual well-being for increasing life expectancy in palliative radiotherapy patients: a questionnaire based study. Journal of Religion and Health 2015; 54: 1563-72.

17. Ariff M, Ashikin M, Maryamjameelah R, Busrah J, Azman WW. Pilot study on the effect of yasiin recitation on the hemodynamics of ventilated patients. The International Medical Journal Malaysia 2013; 12(2): 45-50.

18. Awa S. Effects of holy Qur'an listening on physiological stress response among Muslim patients in intensive care unit. Journal of Management and Muamalah 2014; 5(1): 164-73.

19. Mohamed CR, Nelson K, Wood P, Moss C. Issues post-stroke for Muslim people in maintaining the practice of salat (prayer): a qualitative study. Collegian 2015; 22: 243-9.

20. Zulkarnain NA, Shilawani R, Kadir A, Murat Z, Isa RM. The comparison between listening to Al-Qur'an and listening to classical music on the brain wave signal for the alpha band. Third International Conference on Intelligent Systems Modelling and Simulation 2012: 181-6.

21. Nieswiadomy RM. Foundations of Nursing Research. 4th ed. Upper Saddle River: Pearson Education; 2002.

22. Brislin RW. Back-translation for cross-cultural research. Journal of Cross-Cultural Psychology 1970; 1(3): 185-216.

23. Ciftci H, Otzunc G. The effect of music therapy on comfort, anxiety and pain in the intensive nursing care unit; A case in Turkey. International Journal of Caring Science 2015; 8: 594 63.

24. Besel JM. The effect of music therapy on comfort in mechanically ventilated patient in the intensive care unit Montana State University. 2006: 1-101.

25. O'Brein ME. Spirituality in nursing: Standing on holy ground (Fifth Edition) United States of America: Jones \& Bartlett Learning; 2014.

26. Mahjoob M, Nejati J, Hossein A, Bakhsani NM. The effect of Holy Quran voice on mental health. Journal of Religion and Health 2016; 55(1): 38-42.

27. Mardiyono , Songwathana P, Petpichetchian W. Spirituality intervention and outcomes: Corner stone of holistic nursing practice. Nurse Media Journal of Nursing 2011; 1(1): 117-27.

28. Alhousein AMR, Al-Shaikhli IF, Rahman AW, Alarabi K, Dzulkifli MA. Stress assessment while listening to Quran recitation. International Conference on Computer Assisted System in Health 2014: 68-72.

29. Shekha MS, Hassan AO, Othman SA. Effects of Quran listening and music on electroencephalogram brain. The Egyptian Society of Experimental Biology 2013; 9(1): 119-21.

How to cite: Rustam J.S, Kongsuwan W, Kitrungrote L. Effect of Comfort Care Integrated with the Holy Qur'an Recitation on Comfort of Muslim Patients under Mechanical Ventilation: A Pilot Study. Medical - Surgical Nursing Journal 2017; 6(1): 34-40. 